\title{
Distributed Generation Islanding Effect on Distribution Networks and End User Loads Using the Master-Slave Islanding Method
}

\author{
Lambros Ekonomou ${ }^{1,2}$, George P. Fotis ${ }^{1}$, Vasiliki Vita1, Valeri Mladenov ${ }^{2}$ \\ ${ }^{1}$ Department of Electrical and Electronic Engineering Educators, A.S.PE.T.E.-School of Pedagogical and Technological Education, \\ Athens, Greece \\ ${ }^{2}$ Department of Theoretical Electrical Engineering, Technical University of Sofia, Sofia, Bulgaria \\ Email: leekonomou@aspete.gr, gfotis@gmail.com,vasvita@aspete.gr, valerim@tu-sofia.bg
}

How to cite this paper: Ekonomou, L., Fotis, G.P., Vita, V. and Mladenov, V. (2016) Distributed Generation Islanding Effect on Distribution Networks and End User Loads Using the Master-Slave Islanding Method. Journal of Power and Energy Engineering, 4, 1-24.

http://dx.doi.org/10.4236/jpee.2016.410001

Received: August 7, 2016

Accepted: October 22, 2016

Published: October 25, 2016

Copyright $\odot 2016$ by authors and Scientific Research Publishing Inc. This work is licensed under the Creative Commons Attribution International License (CC BY 4.0).

http://creativecommons.org/licenses/by/4.0/

\begin{abstract}
This study aims to address the feasibility of planned islanding operation and to investigate the effect of unplanned islanding using the master-slave islanding method for controlling the distributed generation units during grid-connected and islanding operation. Neplan desktop power simulation tool was used for the modelling and simulation of a realistic MV network with four different distributed generation technologies (diesel, gas, hydro and wind) along with their excitation and governor control systems, while an exponential model was used to represent the loads in the network. The dynamic and steady state behavior of the four distributed generation technologies were investigated during grid-connected operation and two transition modes to the islanding situation, planned and unplanned. The obtained results that validated through various case studies have shown that a suitable planned islanding transition could provide support to critical loads at the event of electricity utility outages.
\end{abstract}

\section{Keywords}

Distributed Generation, Distribution Networks, Islanding, Master-Slave Islanding Method, Neplan Simulation Tool

\section{Introduction}

In the recent years, there is an increasing interesting for distributed generation (DG) units with their installation to the low and medium voltage level of distribution networks to continuous increase all over world [1]. DG units have brought many significant benefits to electric power networks such as reduction in transmission and distribu- 
tion line losses, improvement of system voltage profiles and the load factor, deferment in capital investments for transmission and distribution networks infrastructure, reduction of emissions and the overall improved system security, efficiency, and reliability [2] [3]. The increasing installations of DGs have also brought several negative impacts such as: increased thermal constrains on utility's assets, voltage level control issues, reversed power flows, and network protection issues which form a significant challenge against further DG deployment [4]-[7]. Protection challenges arise from the fact that DG penetration may pose serious issues on the normal operation of utility protection schemes, such challenges include: false tripping of feeders, blinding of protection, increased or decreased fault levels, unintentional islanding, unsynchronized reclosing, and prevention of automatic reclosing [8].

There is a close relationship between islanding and reclosing problems, as unwanted islands may lead eventually to unsynchronized reclosing. Due to the unpredicted behavior of power systems with unintentional islanding many technical standards state that: any DG unit installed at a distribution feeder must be automatically tripped should the feeder become disconnected from the network, this situation is called: "Anti-Islanding Protection" [8] [9]. Anti-Islanding may reduce DG units' efficiency as well as network reliability if DG units were prevented operation despite of their supply support benefits [1]. New developments in DG technologies such as gas turbines, diesel engines, hydro turbines, and wind energy conversion system (WECS) promises more efficient and greener power production [10]. Many studies have been conducted on distributed generation in terms of generation technology, generation resources availability, supply quality and reliability, as well as protection. While previous work on islanding phenomenon in power systems focused on many different aspects those in particular to this study were related to intentional (planned) and unintentional islanding, anti-islanding detection, and protection from islanding.

Those studies examined the dynamic and steady state behavior of selected systems during grid-connected and islanding operation, hence certain conclusions about islanding whether or not it was a viable option will be made depending on the proposed control strategies as well as the existing DG capacity. While some studies focused on allowing islanding, others aimed to address the problems related to islanding protection and tried to suggest new methods for islanding detection [11] [12]. The results revealed that although wind turbines accounted for small portion of the installed DG capacity, most wind turbines needed to be disconnected in order to preserve system frequency within the permissible range if islanding operation was considered, this is related to the insufficient reserve and inertia issues of intermittent energy sources [12]. The study also suggested a new approach to enable successful islanding with the presence of wind generation and results were promising. This approach was based on demand as frequency controlled reserve (the DFR technology). This technology provides support to islanding frequency at the presence of intermittent generation by performing demand side management on many end-users loads. Since it was found that disconnecting large number of end-users loads such as electric heating, freezers, and refrigerators for short 
period of time not affecting those loads performance but it returns considerable benefit in terms of load reduction to preserve frequency [12]. The unintentional islanding was investigated as a part of an islanding study proposed a power sharing approach to improve the dynamic behavior of an islanded micro-grid system [13]. The dynamic behavior of the islanded part was studied by means of PSCAD/EMTDC software package. The control strategy capability in providing frequency and voltage control to the islanded system was observed. Due to the major contribution from the primary frequency control units, the gas unit added a smoother regulation to the island frequency by injecting less real power. Furthermore, voltage regulation was successful in bringing the bus voltage to the permissible range after unplanned islanding has been detected [13]. A new anti-islanding detection method was proposed [14] as part of new requirement for utilities in order to provide protection from islanding negative impacts such as: outof-phase reclosing, electric shocks from supposedly de-energized islands, and power quality degradation. The new proposed anti-islanding method detects islanding by calculating frequency slip and acceleration between two systems using time synchronized measurements, this method was referred to as islanding detection scheme based on wide-area measurement (IDS_WA) [14]. Results showed that islanding detection scheme based on local area measurement method (IDS_LA) detects islanding successfully if the existing power mismatch between utility grid and DG connected network is large. Meanwhile, IDS_LA failed to establish reliable detection within certain period of time when the power mismatch was small. IDS_WA method managed to detect islanding regardless of the existing power mismatch as simulation results revealed [14].

The current study investigates the feasibility of islanding operation to provide support at the event of utility outages as well as to observe the effect of unintentional islanding on a realistic MV network with four different distributed generation technologies (diesel, gas, hydro and wind) along with their excitation and governor control systems. The master-slave islanding method for controlling the distributed generation units during grid-connected and islanding operation has been used. The obtained results have been validated through various case studies that have shown that a suitable planned islanding transition could provide support to critical loads at the event of electricity utility outages.

\section{Islanding Phenomenon in Power Systems}

Islanding phenomenon is an electrical condition in power distribution networks that involves distributed generation units. It appears when a zone or an area of distribution network supplied by both power grid and DG gets isolated from grid supply due to any reason, and the DG units continue to energize some or the entire load presented within the isolated section. This implies that the distribution utility loses control over supply in the island and can guarantee neither supply quality nor stability [15] [16]. Traditionally, distribution networks used to be passive networks and it did not have any power sources injecting power into grid, therefore any fault used to occur in the network was dealt with by utilities' protection schemes on at basis. However the introduction of DG 
at distribution level made this assumption void and further investigation and research were needed to address the issue of islanding in power systems [17]. In other words, when the amount of power generated by multiple DG units connected at the LV grid matches the absorbed amount of power by loads connected to the same network; utility protection units may fail to detect this situation as no power is flowing through utility grid and that may indicate islanding situation, bearing in mind that DG units may self-disconnect following islanding occurrence without any consideration to the loads presented in the island [16].

Islanding may pose threat to the distribution system especially if it occurs accidentally to a part of the system that was not designed to operate in such conditions. The most potential hazards unintentional islanding may bring to a system if it occurs are the: a) power quality degradation (varied voltage and frequency levels that usually exceed the permissible limits), b)out of phase re-closure, c) loss of grounding (improper grounding of DG units and loads within the island), and d) safety concerns [17] [18]. Concept of islanding detection is based on monitoring the DG units' output parameters and sometimes the grid parameters to notice any change in them, and then conclude whether or not islanding has occurred. On that basis, islanding detection techniques can be categorized into remote and local techniques, while the latter can be divided into passive, active, and hybrid [17]. Remote techniques use certain communication between utility substation and DG. They detect islanding with high degree of reliability and accuracy, however their implementation costs are quite expensive compared to the local techniques [17] [19]. The main principal of local techniques is the measurement of the main electrical parameters (voltage, current, frequency, etc.) at the DG side [19]. Local techniques are sub-categorized into: a) passive techniques that monitor the electric parameters at DG side and compare them with predefined values, b) active techniques that work by injecting certain disturbances at the output of the DG unit and depending on the amount of change in the electric parameters, islanding might be detected if that amount was considerable, and c) hybrid techniques that employ a combination of both active and passive techniques, where active techniques are used when passive techniques suspect islanding situation [17] [19].

\section{Methodology}

\subsection{Conditions for Islanding and Grid-Connected Operation}

DG units are not usually set to participate in regulating the frequency of the grid neither the voltage during a grid-connected mode. They are set to operate in a constant power mode and that is to provide fixed level of real power at high power factor (PF), while the grid frequency and voltage levels are determined by the utility control systems. The governor system attached with those DG units is responsible for providing that constant level of real power, while the excitation and automatic voltage regulation system ensures the constant reactive power output through automatic voltage regulation reference [13] [20].

However, when there is a transition from the grid-connected mode to the islanding 
mode whether it was for intentional or unintentional reasons, these external power control systems are bypassed and new control systems take over depending on the islanding method agreed upon by the utility and the DG units' operators. If this is not the case, then existing governor and excitation control systems remain operating at a predefined reference values chosen according to international standards for safe and stable operation whilst in the islanding mode [13] [20].

Moreover, operating part of the distribution networks in islanding mode needs to take into consideration certain limits for frequency, voltage and harmonics. These limits must be derived from international standards such as those listed in Table 1, and that ensure a safe, reliable, and standard quality supply to all end users loads existing within the island [21]. According to the IEEE 1547-2003 standard, distributed generation units are required to cease energizing the part of the network they supply during certain clearing times should the voltage across the system falls within the correspondent voltage ranges illustrated in Table 2. Clearing time is defined as the time taken by the DG unit to de-energize its supplied part of the network completely after an abnormal condition has occurred [22] [23]. As for the system frequency, according to the IEEE standards 1547-2003 and 1547.2-2008, DG units are required to cease energizing their supplied part of the network within pre-defined clearing times should the system frequency lies within the specified frequency ranges of Table 3. Depending on the DG

Table 1. Standard power systems voltage and frequency limitations [21].

\begin{tabular}{ccc}
\hline Voltage Window & Frequency Window & Reference Standard \\
\hline 0.9 to $1.1 \mathrm{U}_{\mathrm{N}}$ & 0.99 to $1.01 \mathrm{f}_{\mathrm{N}}$ & IEEE P1547 \\
0.8 to $1.15 \mathrm{U}_{\mathrm{N}}$ & 0.94 to $1.02 \mathrm{f}_{\mathrm{N}}$ & VDE 0126, OVE E2750 (partly) \\
0.8 to $1.2 \mathrm{U}_{\mathrm{N}}$ & 0.994 to $1.006 \mathrm{f}_{\mathrm{N}}$ & DK 5950 \\
\hline
\end{tabular}

Table 2. IEEE abnormal voltage range clearing times [22].

\begin{tabular}{cc}
\hline Voltage Range (Percentage of Nominal Voltage) & Clearing Time in Seconds \\
\hline $\mathrm{V}<50 \%$ & 0.16 \\
$50 \% \leq \mathrm{V}<88 \%$ & 2 \\
$88 \% \leq \mathrm{V}<110 \%$ & Normal Operation \\
$110 \% \leq \mathrm{V}<120 \%$ & 1 \\
$\mathrm{~V} \geq 120 \%$ & 0.16 \\
\hline
\end{tabular}

Table 3. IEEE abnormal frequency range clearing times [22].

\begin{tabular}{ccc}
\hline DG Capacity & Frequency Range & Clearing Time in Seconds \\
\hline \multirow{2}{*}{$\mathrm{DG} \leq 30 \mathrm{~kW}$} & $49.4 \leq 50.4$ & 0.16 \\
& $\mathrm{f}<49.4$ & Normal Operation \\
& $\mathrm{f}>50.4$ & 0.16 \\
& $49.8 \leq \mathrm{f} \leq 50.4$ & 0.16 \\
$\mathrm{DG}>30 \mathrm{~kW}$ & $47.5 \leq \mathrm{f}<49.8$ & Normal Operation \\
& $\mathrm{f}<47.5$ & Adjustable $0.16-300$ \\
\hline
\end{tabular}


unit capacity the frequency limits and their correspondent clearing times may be fixed or field adjustable. In order to make the islanding mode a feasible option, two key states need to be addressed, studied, and planned fully and completely. Those states are: a) the transition from grid-connected into islanding mode, and b) island operation after disconnection from utility control [24].

\subsection{Master-Slave Islanding Method}

This islanding strategy aims to adjust the control systems of a selected DG unit following the transition to islanding situation. This adjustment will change the control mode from fixed power generation control (P-Q) to become fixed frequency and voltage regulation control (V-f), thus the selected DG unit will be acting as a swing source and is called the master unit [20] [25] [26]. However, the remaining DG units in the island will not see any changes to their control systems and they will remain the same as grid-connected operation and that is constant power control (P-Q), hence those units are called slave units. Operational power values of the slave units will normally be determined by an auxiliary control system of the master unit and it will be sent via slow communication channels between the master DG unit and the rest of slave DG units within the island.

\section{Distribution System Description}

The test network used for this study (Figure 1), is part of a realistic MV network with a nominal voltage of $20 \mathrm{kV}$ [27]; it consists of the utility main feeder NETZ rated at 110 $\mathrm{kV}$, with (2000 - 1000) MVA for max-min initial symmetrical short circuit apparent power. The HV/MV part of the network consists of two transformers each rated at $110 / 20 \mathrm{kV}$, and 30 MVA rated apparent power. The MV network consists of five feeders, while the investigated part of that network Feeder\#2 is connected to the MV network at the point of common coupling; this feeder consists of four generators which is the scope of interest for the examined case studies. The remaining two generators are connected to feeders number 3 and 4 respectively. Technical data of the six distributed generators can be found in Table 4. All of the feeders' lines are made of copper cable lines with a cross sectional dimension of $3 \times(1 \times 95) \mathrm{mm}^{2}$, the corresponding lengths for all the lines in the MV network are illustrated in Table 5 [27].

Table 4. DG units' characteristics [27].

\begin{tabular}{cccc}
\hline Generator Name & Rated Nominal Voltage $(\mathrm{kV})$ & Rated Apparent Power (MVA) & Neutral Point \\
\hline GEN1 & 20 & 3 & Ungrounded \\
GEN2 & 20 & 3 & Ungrounded \\
GEN3 & 20 & 3 & Ungrounded \\
GEN4 & 20 & 3 & Ungrounded \\
GEN5 & 20 & 3 & Ungrounded \\
GEN6 & 20 & 3 & Ungrounded \\
\hline
\end{tabular}


Table 5. Test network lines lengths in $\mathrm{km} \mathrm{[27].}$

\begin{tabular}{cccccc}
\hline Line Name & Length $(\mathrm{km})$ & Line Name & Length $(\mathrm{km})$ & Line Name & Length $(\mathrm{km})$ \\
\hline L1-1 & 1.00 & L2-7 & 0.50 & L4-3 & 1.00 \\
L1-2 & 0.50 & L2-8 & 0.70 & L4-4 & 0.80 \\
L1-3 & 0.80 & L2-9 & 0.70 & L4-5 & 0.50 \\
L1-4 & 0.80 & L2-10 & 0.70 & L4-6 & 0.50 \\
L1-5 & 1.00 & L2-11 & 1.00 & L5-1 & 0.50 \\
L2-1 & 0.50 & L3-1 & 1.00 & L5-2 & 0.80 \\
L2-2 & 0.50 & L3-2 & 1.00 & L5-3 & 0.80 \\
L2-3 & 0.80 & L3-3 & 1.00 & L5-4 & 1.00 \\
L2-4 & 1.00 & L3-4 & 1.00 & L5-5 & 0.70 \\
L2-5 & 1.00 & L4-1 & 1.50 & & \\
L2-6 & 1.00 & L4-2 & 0.80 & & \\
\hline
\end{tabular}

The remaining part of the MV network, the loads, is as follows: Loads L1-1 to L1-5, L3-1 to L3-3, L4-1 to L4-6, and L5-1 to L5-5 are all with 0.8 MVA apparent powers with 0.95 lagging PF [27]. As for loads on the studied Feeder\#2, they are as follows: L2-1, L2-2, L2-5, L2-8, L2-9, L2-11, and L2-12 are rated at 0.4 MVA, while loads L2-3, L2-4, L2-6, L2-7, and L2-10 are rated at 0.8 MVA; all loads are with 0.95 lagging PF [27]. This MV network is shown in Figure 1.

\section{Dynamic Models of the Network Components}

\subsection{The Load Model}

The load model selected for the purpose of the dynamic simulation is a static exponential load model. Naturally, loads consist of static and dynamic components which are derived from the nature of the load whether it was residential, commercial, or industrial. Static load models describe the dependency of load active and reactive power as function of the system voltage and/or frequency at one specific instant of time. While on the other hand dynamic load models describe this relation at any instant of time, hence static load models are not time dependent [28]. However, static load models have been sufficient enough to be used for a very long time to study load behavior for both the static and dynamic components [28], therefore and for the sake of simplicity the static exponential load model has been used throughout this study to describe the static components for all the loads presented in the island and to approximate their dynamic components.

Equations that can describe the load power dependency as function of system voltage and frequency under the static exponential load model are [29] [30]:

$$
P=P_{0}\left(\frac{U}{U_{0}}\right)^{n P}\left(1+\frac{\Delta f}{f_{0}} F_{p}\right)
$$




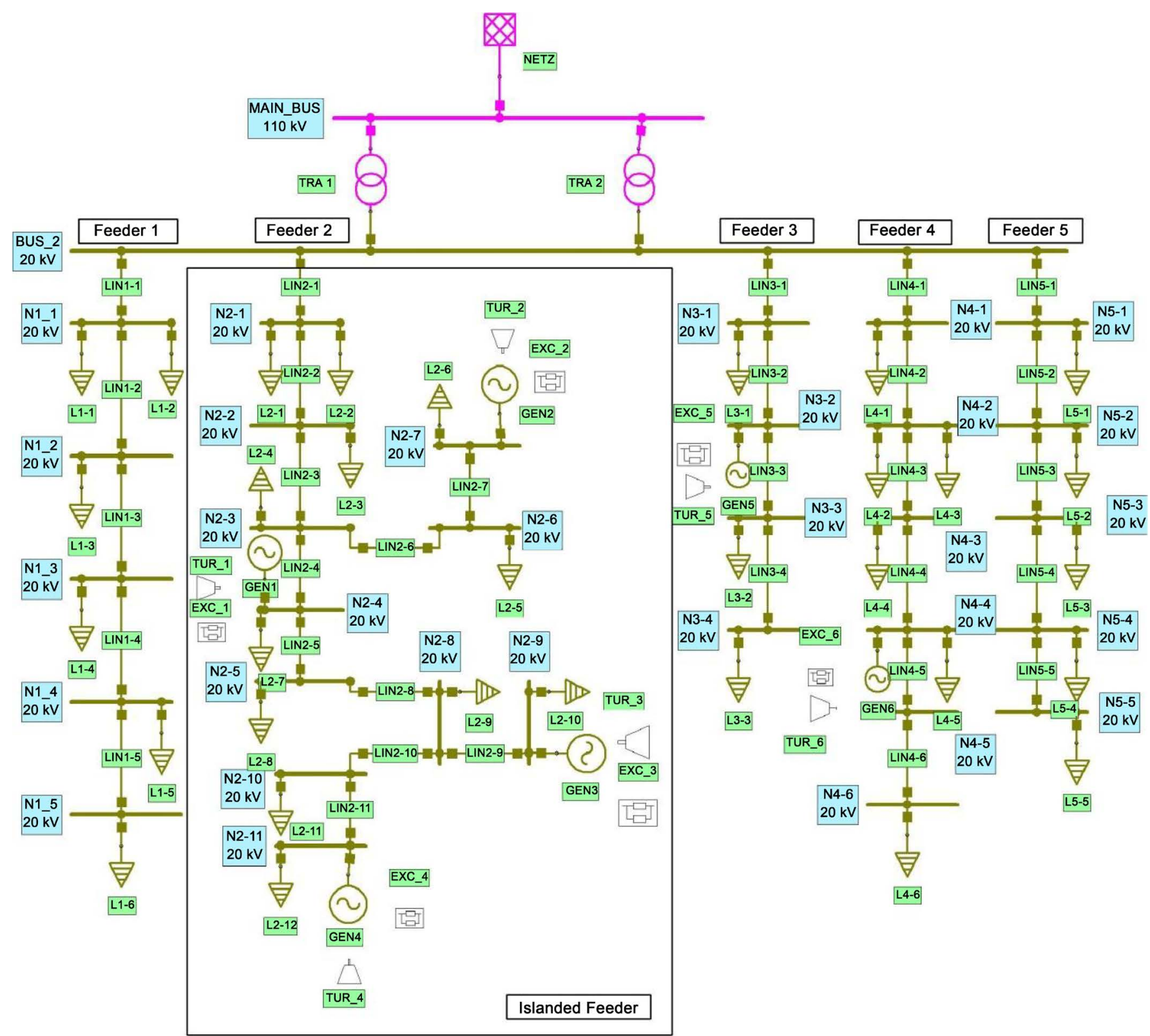

Figure 1. Studied network single line diagram.

$$
Q=Q_{0}\left(\frac{U}{U_{0}}\right)^{n Q}\left(1+\frac{\Delta f}{f_{0}} F_{q}\right)
$$

where:

$P$ : is the ongoing active power of the load,

$Q$ : is the ongoing reactive power of the load,

$P_{0}$ : is the nominal active power of the load,

$Q_{0}$ : is the nominal reactive power of the load,

$U$ : is the magnitude of ongoing node voltage,

$U_{0}$ : is the nominal system voltage, 
$f_{0}:$ is the rated system frequency,

$\Delta f:$ is frequency difference from rated frequency,

$n P$ : is the dependence of load active power on voltage,

$n Q$ : is the dependence of load reactive power on voltage,

$F_{p}:$ is the dependence of load reactive power on frequency, and

$F_{q}:$ is the dependence of load reactive power on frequency.

Typical values for the loads used for all four case studies dynamic simulation were [28]:

$$
n P=1, n Q=2,=0 \text { and }=-1
$$

\subsection{DG Units}

The diesel, gas and hydro DG Units are modeled as a single-mass synchronous machine. The machine electrical system is represented in the d-q-0 frame with two rotor windings on each axis. The excitation and governor systems of the machine are also included in the simulation model. The parameters for the diesel, gas and hydro units dynamic model used in this study are shown in Table 6. The wind DG unit is modeled as a direct drive synchronous generator. Rotor and generator shafts are mounted to the same shaft without gear-box. The generator is a permanent magnet synchronous generator designed for low speed. The permanent magnet machine dynamic model used for this study is the one embedded in Neplan and has the parameters of Table 6. Permanent magnet synchronous generator output is injected to the utility grid through backto-back pulse width modulator (PWM) convertor. The convertor system ensures that both generator and grid currents are sinusoidal and it can enable for variable speed control. To achieve regulation of the current components for the grid side PWM, the regulator used ensures regulation for both $\mathrm{d}$-axis and q-axis of the current components in a very fast inner control loop. Meanwhile, the slower outer control loop that regulates the reactive and active powers is used to define the current references [31].

\section{Case Studies}

The distribution network was built using Neplandesktop power systems simulation tool and according to each case study the correspondent distributed generation technology

Table 6. Synchronous machine dynamic model parameters for the four different types of DG units.

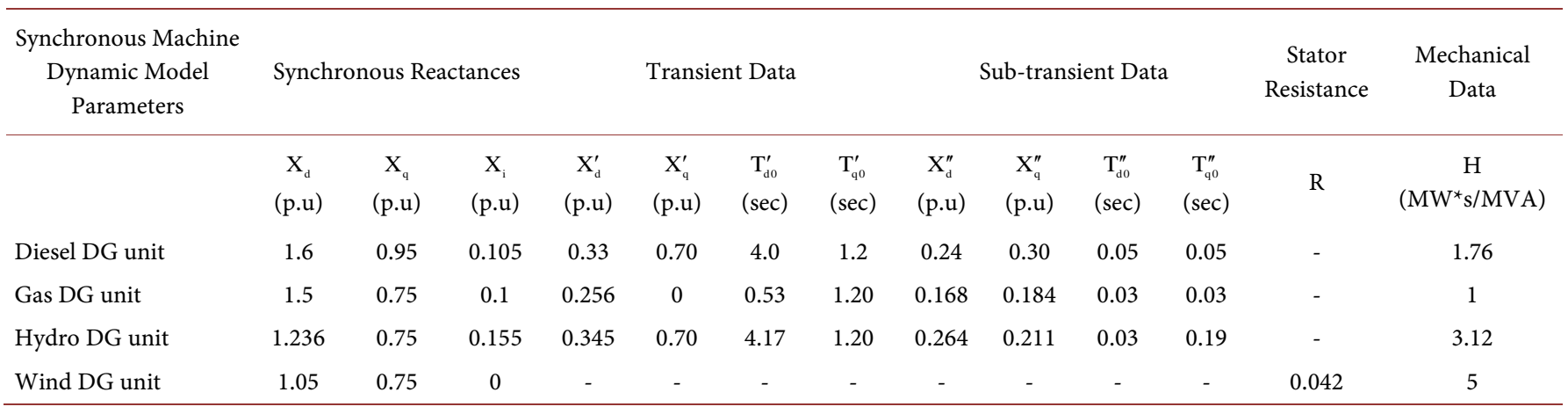


is injected to the network on Feeder\#2 to enable the study of the dynamic behavior of each DG technology following an islanding occurrence under the same operational values for the rest of the network components.

The current IEEE standards prevent the operation of distribution system in islanded conditions, where the DG unit is still supplying part of or the total load within an island at the event of utility outage. This is related to system control, protection, and personnel safety issues [24]. The current control scheme in the network normally trips the DG units within 2 seconds as indicated earlier in the standard voltage and frequency clearing times (Table 2 and Table 3). However it is assumed that those clearing times were adjusted and relaxed to enable the planned and unplanned islanding operation to run smoothly without interruption by the utility's protection units during the tests for all of the four case studies. The total rated system load distributed throughout Feeder\#2 for the following four case studies is set to be $(6.46+\mathrm{j} 2.125) \mathrm{MVA}$, however depending on the dynamic response of the load this rated value may undergo slight changes according to the type of units presented in the island as well as the islanding method used.

In this study, it is assumed that the DG units are considered for autonomous operation at the planning stage. This implies that all the used DG units have the capability by working together for each case study, within the range of their rated power, to supply the total load in the islanded part of the network without affecting the island desirable operational voltage and frequency limits. This level of power redundancy ensures that no loads in the islanded part of the network have to be disconnected during the islanding mode to re-establish the generation with demand balance in real time [32] [33].

The dynamic response of the system is studied in the four case studies by observing the changes in frequency, voltage, real power, and reactive power across the islanded section following the transition from utility connected mode to islanded mode using the master-slave islanding method. Two transition conditions were used throughout the first three case studies using the disturbances of the dynamic transient stability module inside the used power simulation tool Neplan, these are: CB opening (by opening a logical switch on the upper or lower side of line LIN2-1) and that demonstrated the planned islanding transition condition, while the other transition condition, the unplanned islanding, was achieved by triggering a three phase short circuit fault at line (LIN2-1) at a certain distance on the line and that caused the line to be tripped from both sides after some deci-seconds due to the assumed protection scheme used by the local utility. As for the forth case study, only one transition condition was used in order to less complicate the case, hence only the planned islanding transition was used.

\subsection{Case Study A: Islanding of Diesel Only Units}

In this case study all four DG units (GEN1, GEN2, GEN3, GEN4) are diesel based units connected to buses N2_4, N2_7, N2_9, and N2_11 respectively as illustrated in Figure 1. In this sub-case scenario, GEN_D2 is selected to be the master DG unit and it was set to operate at $60 \%$ of its rated capacity with almost unity PF of 0.99 (i.e., $(1.8+j 0.25)$ MVA), while the remaining there DG units were selected as slave DG units and were 
set to operate at $50 \%$ of their rated capacity with $0.95 \mathrm{PF}$ (i.e., $(1.5+\mathrm{j} 0.5)$ MVA each). Neplan has been configured to allow the control systems of GEN_D2 to become (V-f) control following the islanding occurrence, while to keep the remaining three DG units Gen_D1, Gen_D3, and Gen_D4 as constant generation in (P-Q) control through maintaining the pre-configured state of control for their governor and excitation systems before and after the islanding mode.

\subsubsection{Planned Islanding of the Diesel Units (Case A1)}

As mentioned earlier the transition from the grid-connected mode to the islanding mode occurred by opening the upper CB of LIN2-1 at $\mathrm{t}=2$ seconds. The results obtained from the dynamic simulation are shown in Figure 2.

\subsubsection{Unplanned Islanding of the Diesel Units (Case A2)}

In this sub case scenario the transition from grid-connected mode to island mode oc-

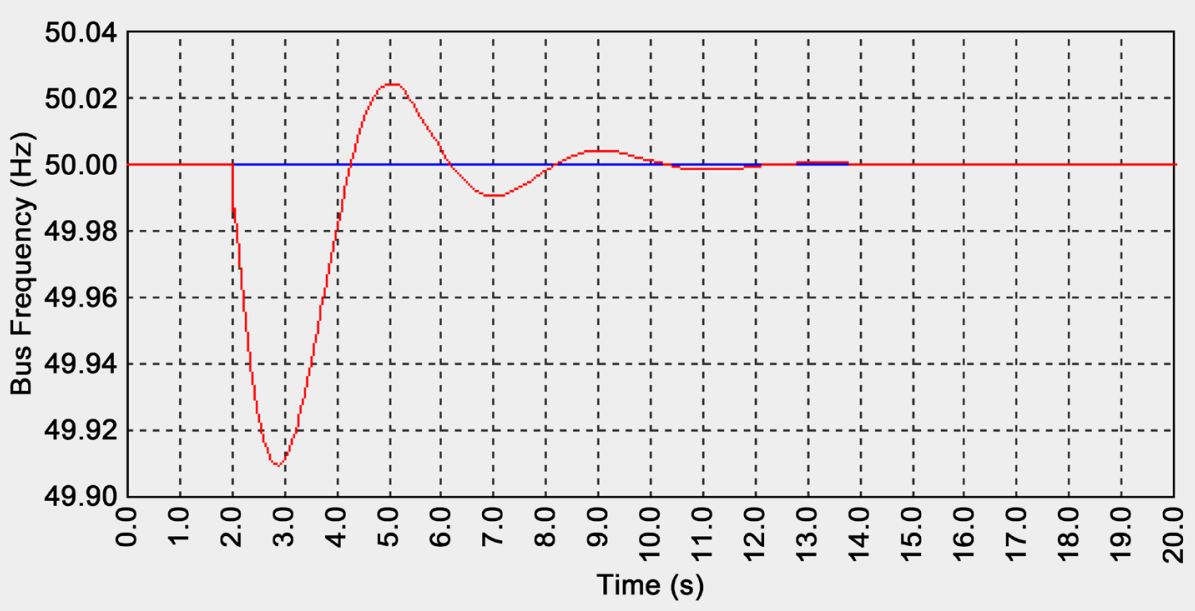

Master-Slave: N2-4-WEI Master-Slave: N2-9-WEI——Master-Slave: N2-7-WEI——Master-Slave: BUS_2-W— Master-Slave: N2-11-WE

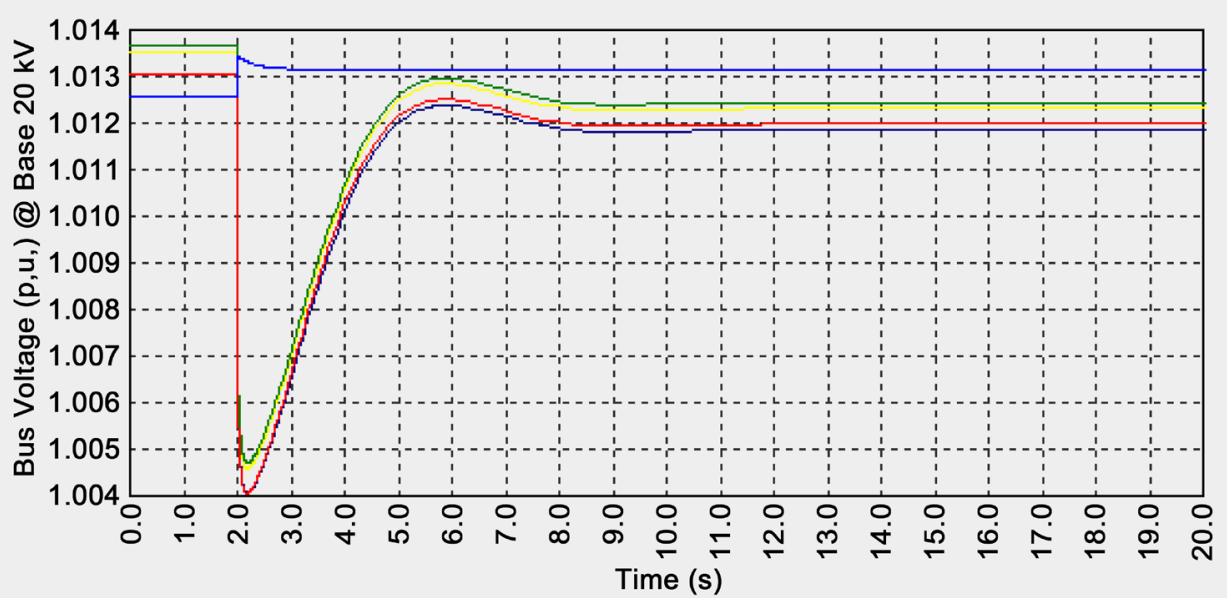

Master-Slave: N2-4-VT

Master-Slave: N2-9-VT— Master-Slave: N2-11-VT—— Master-Slave: N2-7-VT—— Master-Slave: BUS_2-VT

Figure 2. Diesel case master-slave planned islanding results (case A1). 


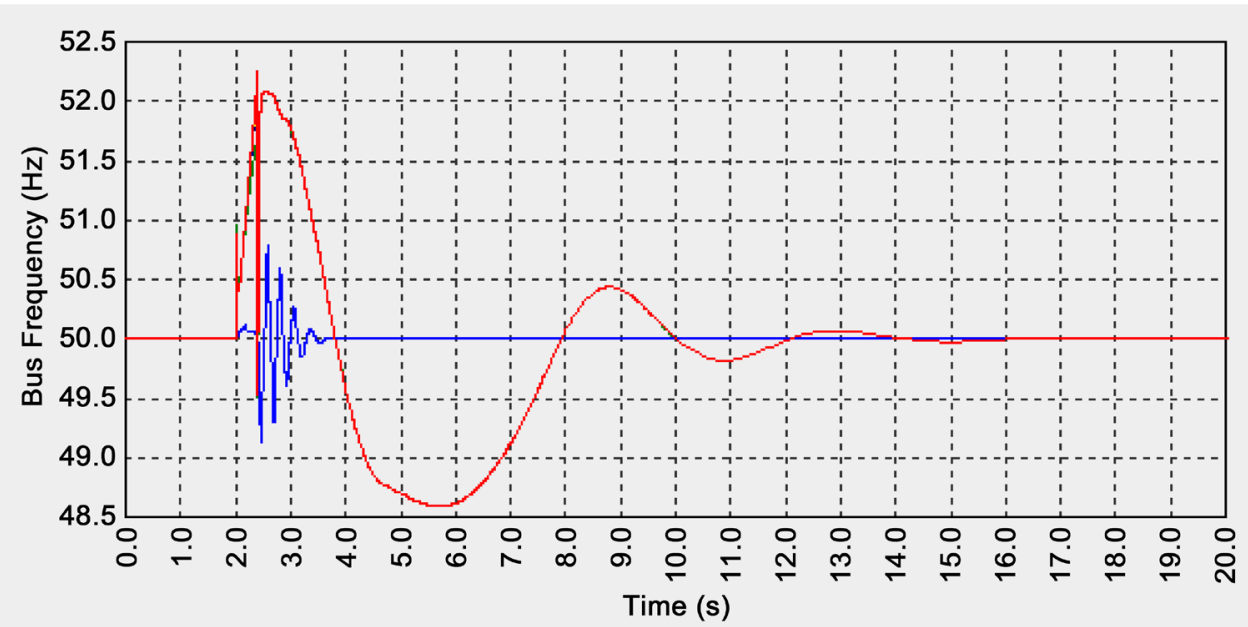

Master-Slave: N2-4-WEI Master-Slave: N2-9-WEI —-Master-Slave: N2-7-WEI — Master-Slave: BUS_2-W—Master-Slave: N2-11-WE

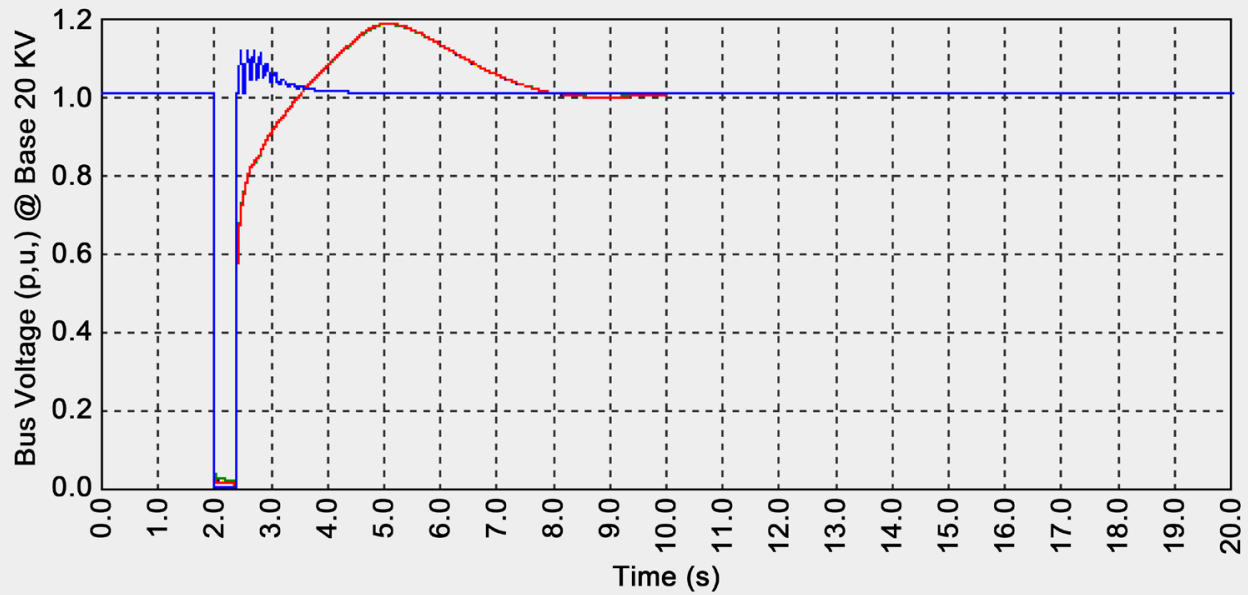

Master-Slave: N2-4-VT

Master-Slave: N2-9-VT —_ Master-Slave: N2-11-VT_ Master-Slave: N2-7-VT — Master-Slave: BUS_2-VT

Figure 3. Diesel case master-slave unplanned islanding results (case A2).

curred by setting a 3-phase fault at LIN2-1 at $\mathrm{t}=2$ seconds and opening both CB's at both ends of LIN2-1 to clear the fault at $t=2.4$ seconds. After running the simulation, results were obtained as shown in Figure 3.

\subsection{Case Study B: Islanding of Gas Only Units}

In this case study all four DG units (GEN1, GEN2, GEN3, GEN4) are gas type units connected to buses N2_4, N2_7, N2_9, and N2_11 respectively as illustrated in Figure 1. The master unit was set as GEN_G2 and was loaded at $60 \%$ of its rated capacity with almost unity PF of 0.99 (i.e., $(1.8+\mathrm{j} 0.25) \mathrm{MVA}$ ) which was the case for the diesel master unit. As for the slave units Gen_G1, Gen_G3, and Gen_G4 they were loaded by $50 \%$ of their rated capacity with $0.95 \mathrm{PF}$ (i.e., $(1.5+\mathrm{j} 0.5) \mathrm{MVA}$ each), again the same as the slave units of the previous case study. Neplan has been configured to allow the control system of GEN_G2 (the master unit) to become (V-f) control following the islanding 
occurrence, while to keep the remaining slave units in constant generation as (P-Q) control before and after islanding.

\subsubsection{Planned Islanding of the Gas Units (Case B1)}

For this sub case scenario, the planned transition was achieved again by opening CB of LIN2-1 at $\mathrm{t}=2$ seconds. The obtained results are presented in Figure 4.

\subsubsection{Unplanned Islanding of the Gas Units (Case B2)}

In this sub case scenario, the transition occurred by setting a 3-phase fault at LIN2-1 at $\mathrm{t}=2$ seconds and then clearing the fault at $\mathrm{t}=2.2$ seconds by opening both $\mathrm{CB}$ on LIN2-1. The obtained simulation results are shown in Figure 5.

\subsection{Case Study C: Islanding of Hydro Only Units}

In this case study all four DG units (GEN1, GEN2, GEN3, GEN4) are hydro units con-

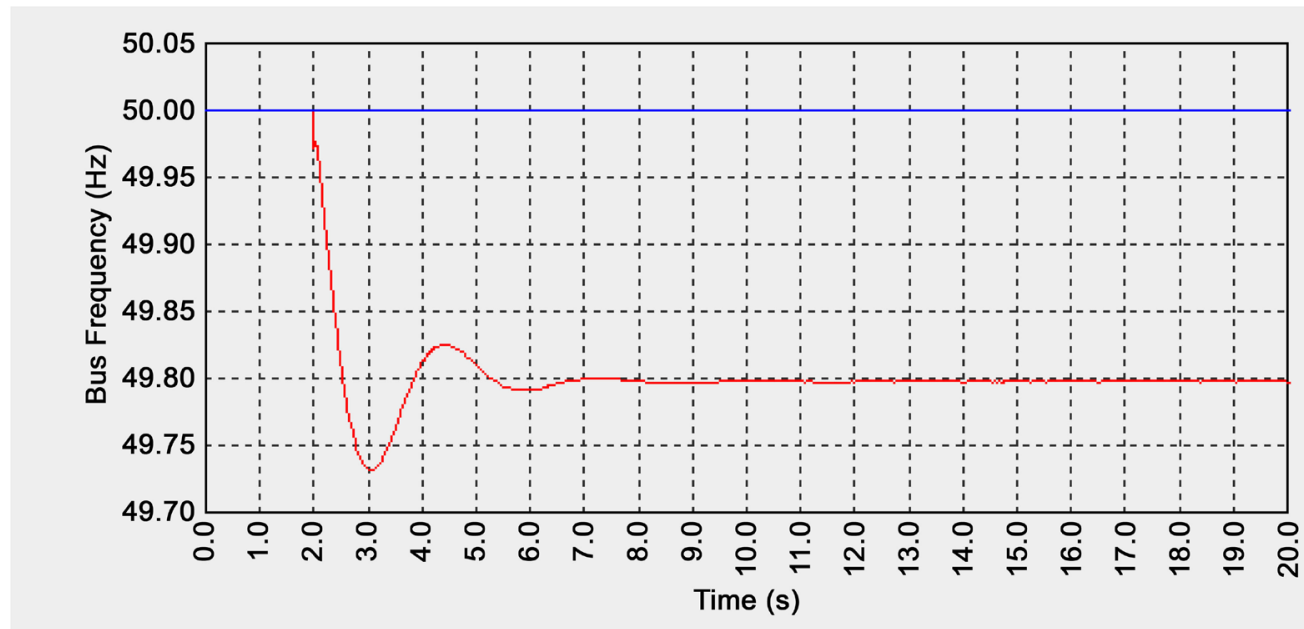

Master-Slave: N2-4-WEI Master-Slave: N2-9-WEI_— Master-Slave: N2-7-WEI—— Master-Slave: BUS_2-W —— Master-Slave: N2-11-WE

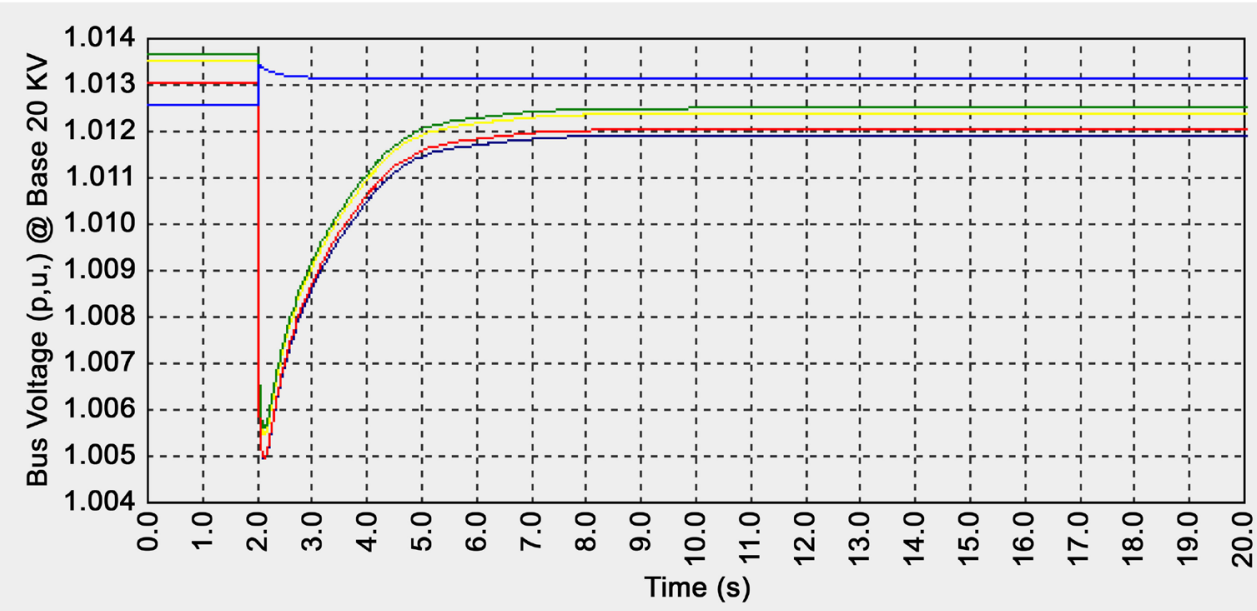

Master-Slave: N2-4-VT

Master-Slave: N2-9-VT — Master-Slave: N2-11-VT_— Master-Slave: N2-7-VT — Master-Slave: BUS_2-VT

Figure 4. Gas case master-slave planned islanding results (case B1). 


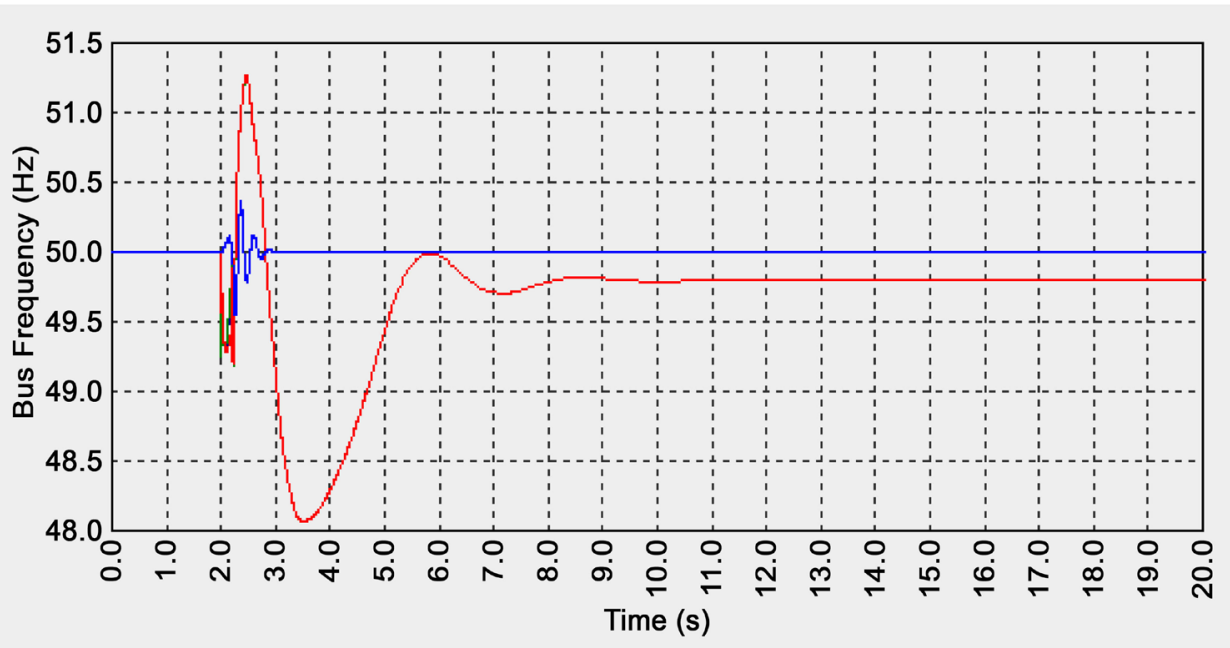

Master-Slave: N2-4-WBL_Master-Slave: N2-9-WBL_-Master-Slave: N2-11-WB_—Master-Slave: N2-7-WBL_— Master-Slave: BUS_2-WBL

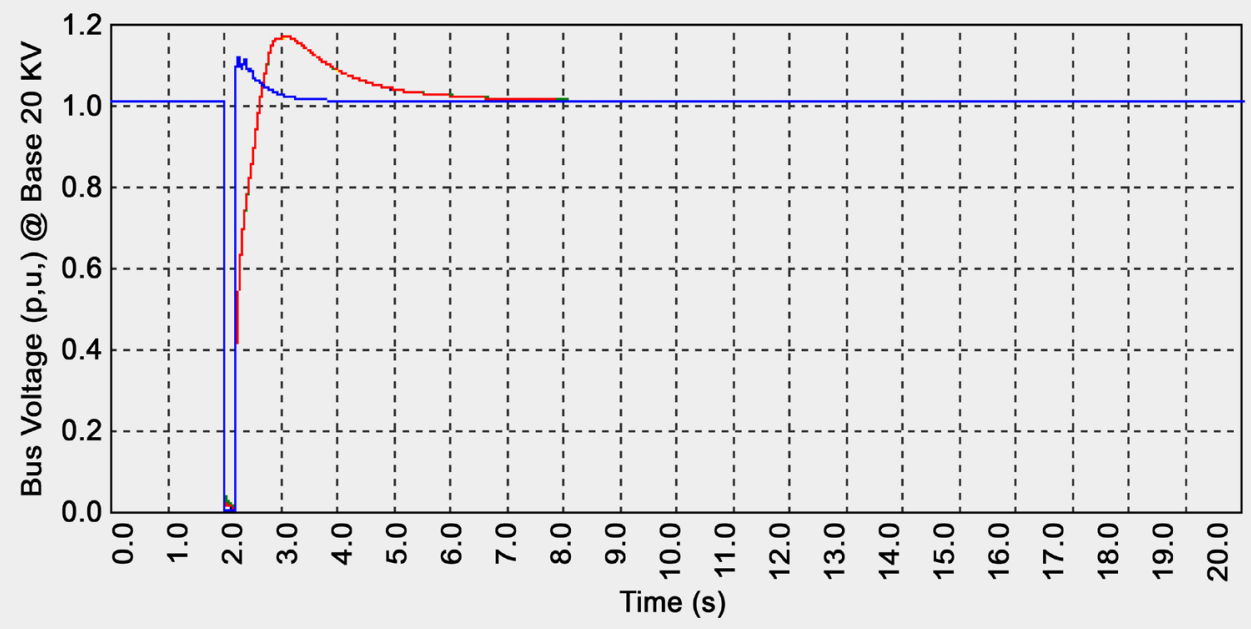

Master-Slave: N2-4-VT Master-Slave: N2-9-VT

Master-Slave: N2-11-VT

Master-Slave: N2-7-VT — Master-Slave: BUS_2-VT

Figure 5. Gas case master-slave unplanned islanding results (case B2).

nected to buses N2_4, N2_7, N2_9, and N2_11 respectively as illustrated in Figure 1. In this sub-case scenario, the selection of the master and slave units was set to follow exactly the same settings of the previous two case studies for the sake of continuity and establishing an equal foundation to base the conclusions. Hence, GEN_H2 was the master unit while Gen_H1, Gen_H3, and Gen_H4 were selected as the slave units. Also they were loaded at $60 \%$ of rated capacity with $0.99 \mathrm{PF}$ and $50 \%$ of rated capacity with $0.95 \mathrm{PF}$ for master and slave units respectively (i.e., master at $(1.8+\mathrm{j} 0.25) \mathrm{MVA})$ and slaves at $(1.5+\mathrm{j} 0.5)$ MVA each).

Neplan has been configured to change the control system of Gen_H2 from (P-Q) to (V-f) control following islanding in order to follow the islanding transients and recover the system voltage and frequency, while to keep the (P-Q) control mode for the remaining slave units before and after islanding. 


\subsubsection{Planned Islanding of the Hydro Units) (Case C1)}

In this sub-case scenario, the transition procedures were achieved again by opening $\mathrm{CB}$ of LIN2-1 at $\mathrm{t}=2$ seconds exactly as in the planned master-slave islanding of the diesel and gas units in the previous two case studies. After running the simulation, results were obtained as shown in Figure 6.

\subsubsection{Unplanned Islanding of the Hydro Units (Case C2)}

In this sub-case scenario, the unplanned transition was identical to the one of the gas master-slave unplanned islanding sub-case. The obtained simulation results are shown in Figure 7.

\subsection{Case Study D: Islanding of Mixed Units}

In this case study two WECS (wind energy conversion system) were modelled via Neplan. The single line diagram that relates to each WECS is shown in Figure 8(a) and

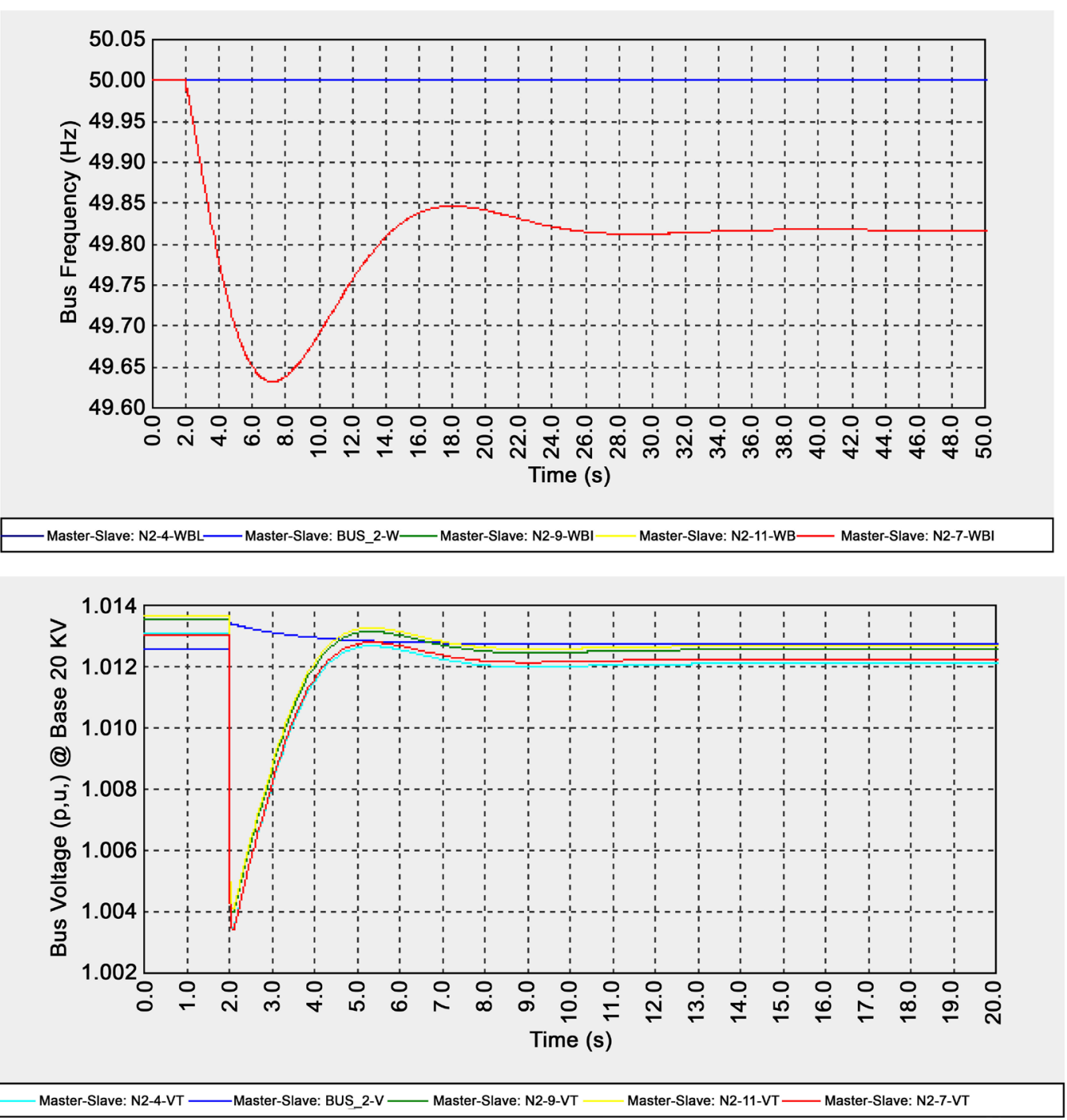

Figure 6. Hydro case master-slave planned islanding results (case C1). 


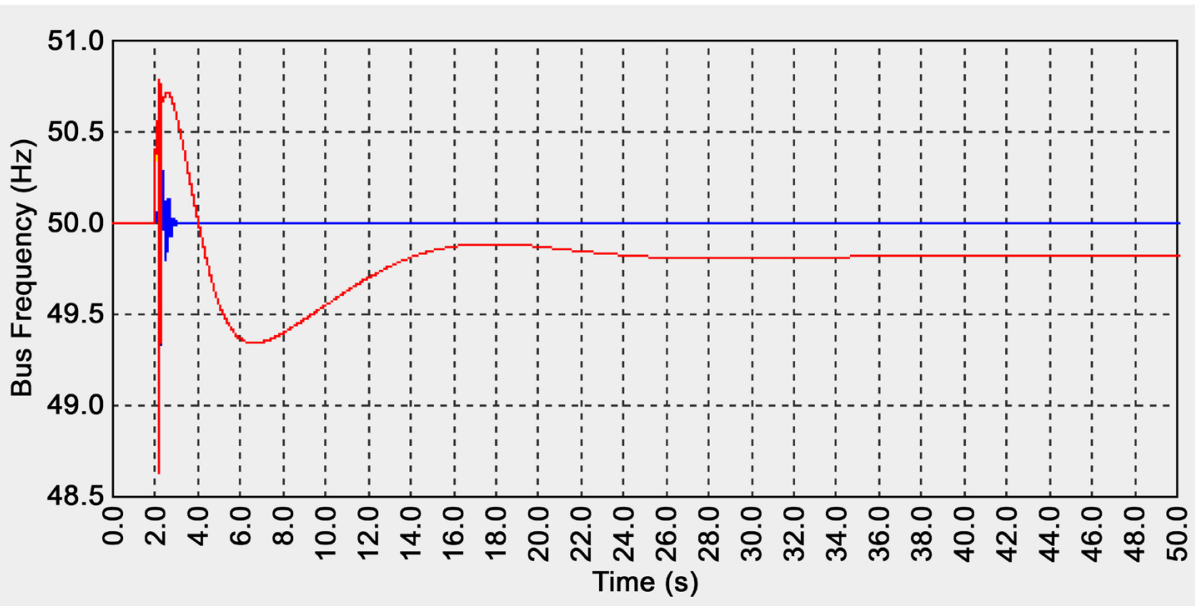

Master-Slave: N2-4-WBL_— Master-Slave: BUS_2-W——Master-Slave: N2-9-WBI_ Master-Slave: N2-11-WB_— Master-Slave: N2-7-WBI

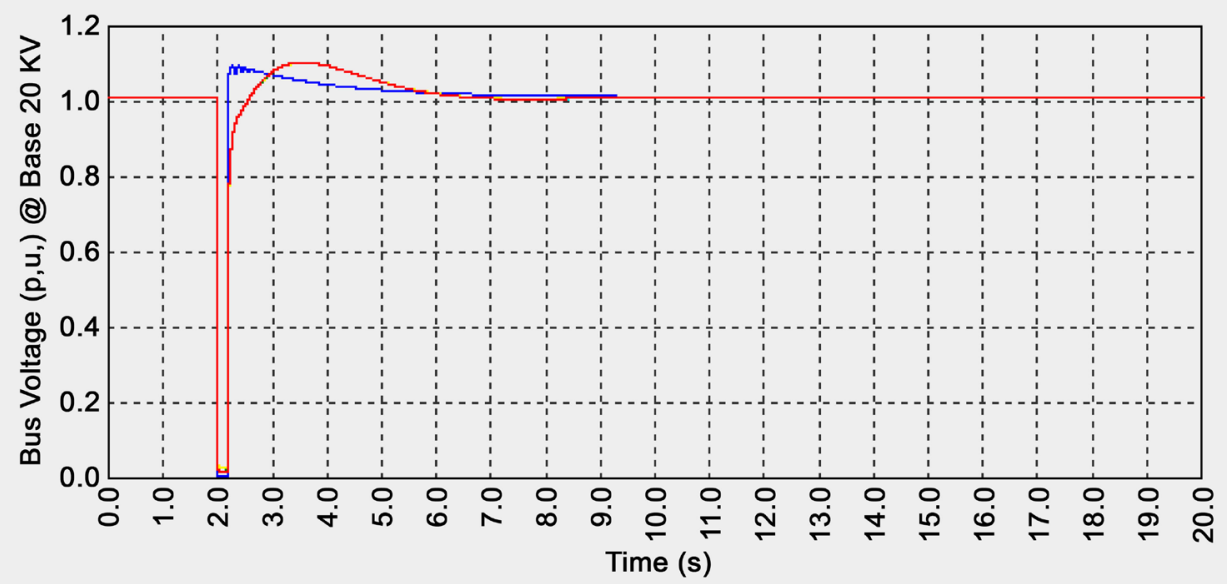

Master-Slave: N2-4-VT_— Master-Slave: BUS_2-V—— Master-Slave: N2-9-VT_ Master-Slave: N2-11-VT—— Master-Slave: N2-7-VT

Figure 7. Hydro case master-slave unplanned islanding results (case C2).

Figure 8(b). Each wind DG unit has a rated capacity of 2 MVA and $3.3 \mathrm{kV}$ rated voltage, and were connected to the investigated feeder via a (20/3.3) kV, 2MVA transformer at the correspondent bus. WECS single line diagrams were built under different network layer in Neplan and were shortened at the main network diagram as Gen_W1 and Gen_W2 to avoid congestion on the main diagram. Both WECS's were connected to Feeder\#2 at buses N2-4 and N2-7 respectively, this WECS layout and point of connection were the same for the following three sub-case studies. Generators PMSM1 and PMSM2 were configured to operate in (P-Q) mode before and after islanding, and were loaded at $75 \%$ of their rated capacity with a unity PF (i.e., $(1.5+j 0)$ MVA).The master-slave islanding method was applied to the remaining other DG technologies (diesel, gas, and hydro), however no changes occurred to those units in terms of unit ratings. Therefore, each unit had 3 MVA rated capacity and a $20 \mathrm{kV}$ rated voltage. The prementioned situation regarding the four DG technologies remained unchanged during the simulation of the following three sub-case scenarios. Table 7 demonstrates DG 
units' arrangements for the purpose of the mixed case.

\subsubsection{Planned Islanding of Two Diesel \& Two Wind Units (Case D1)}

In this sub-case scenario the two DG Units (Gen_W1, Gen_W2) are two wind based units connected to buses N2-4 and N2-7 respectively, while the other two DG diesel based units (Gen_D1 and Gen_D2) are connected to buses N2-9 and N2-11, respectively of Figure 1. In this sub-case, Gen_D1 was selected as the master unit while Gen_D2 was the slave one. The pre-islanding situation was as follows: master and slave

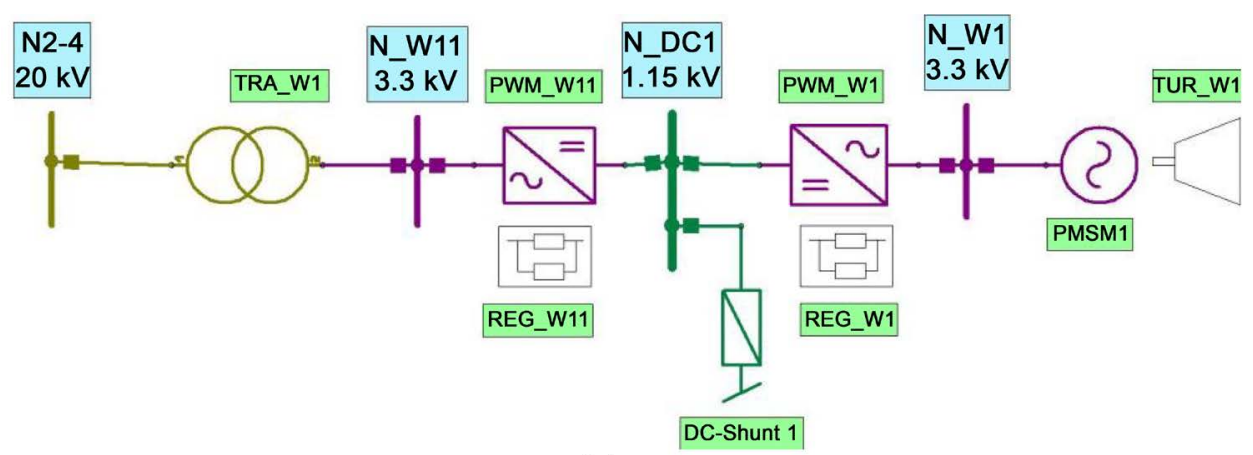

(a)

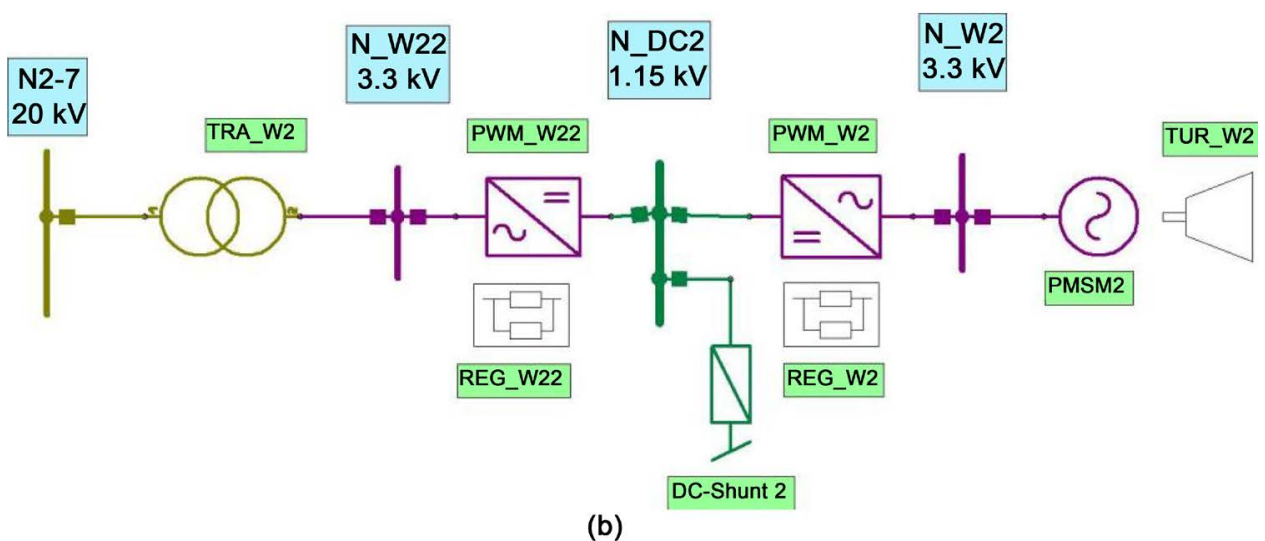

Figure 8. WECS single line diagram: (a) unit 1 and (b) unit 2.

Table 7. DG units' arrangements for the purpose of the mixed case.

\begin{tabular}{ccccc}
\hline $\begin{array}{c}\text { Generator } \\
\text { Name }\end{array}$ & $\begin{array}{c}\text { Correspondent Gen. } \\
\text { Name (wind \&diesel } \\
\text { sub-case) }\end{array}$ & $\begin{array}{c}\text { Correspondent Gen. } \\
\text { Name (wind \&gas } \\
\text { sub-case) }\end{array}$ & $\begin{array}{c}\text { Correspondent Gen. } \\
\text { Name (wind \&hydro } \\
\text { sub-case) }\end{array}$ & $\begin{array}{c}\text { Correspondent } \\
\text { Node of } \\
\text { Connection }\end{array}$ \\
\hline GEN & Gen_W1 & Gen_W1 & Gen_W1 & N2-4 \\
GEN & Gen_W2 & Gen_W2 & Gen_W2 & N2-7 \\
GEN & GEN_D1 & GEN_G1 & GEN_H1 & N2-9 \\
GEN & GEN_D2 & GEN_G2 & GEN_H2 & N2-11 \\
GEN & GEN5 & GEN5 & GEN5 & N3-2 \\
GEN & GEN6 & GEN6 & GEN6 & N4-4 \\
\hline
\end{tabular}


units were loaded at $(1.8+j 0.25)$ MVA and $(1.5+j 0.5)$ MVA respectively, while wind units were loaded at $(1.5+j 0)$ MVA. The obtained simulation results are shown in Figure 9.

\subsubsection{Planned Islanding of Two Gas \& Two Wind Units (Case D2)}

In this sub-case, Gen_G1 was selected as the master unit while Gen_G2 was the slave one. The pre-islanding situation was exactly as the pervious sub-case scenario. The obtained simulation results are shown in Figure 10.

\subsubsection{Planned Islanding of Two Hydro \& Two Wind Units (Case D3)}

In this sub-case, Gen_H1 was selected as the master unit while Gen_H2 was the slave one. The pre-islanding situation was exactly as sub-case D1. The obtained simulation results are shown in Figure 11.

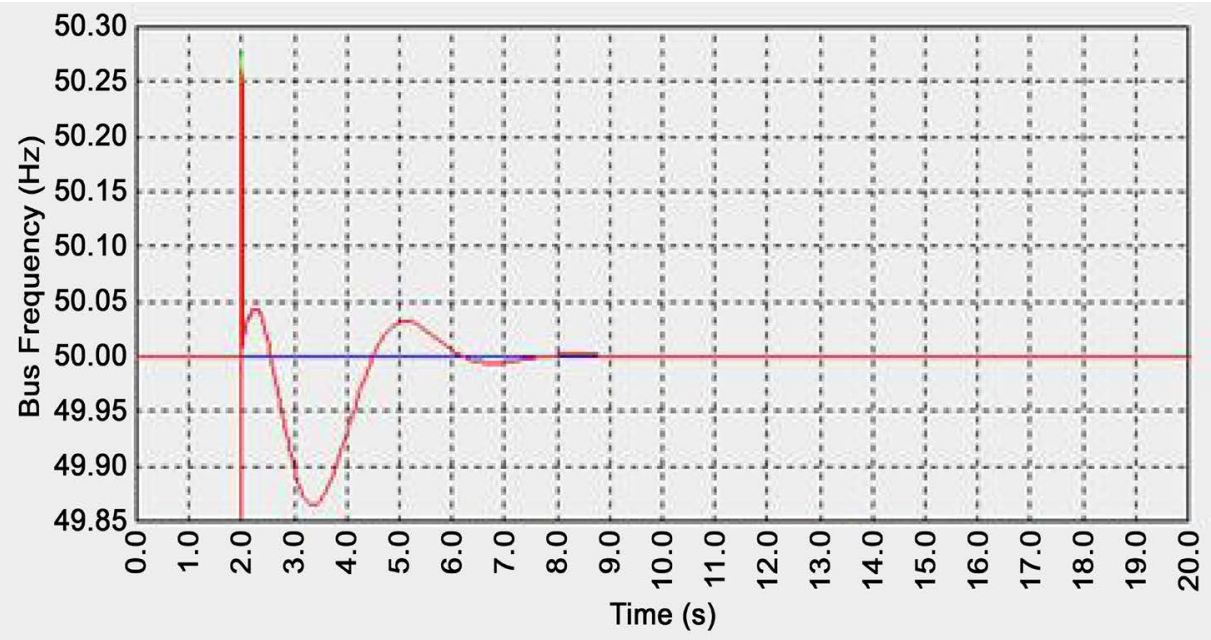

Master-Slave: BUS_2-WI Master-Slave: N2-4-WEI— Master-Slave: N2-9-WEI Master-Slave: N2-7-WBI— Master-Slave: N2-11-WE

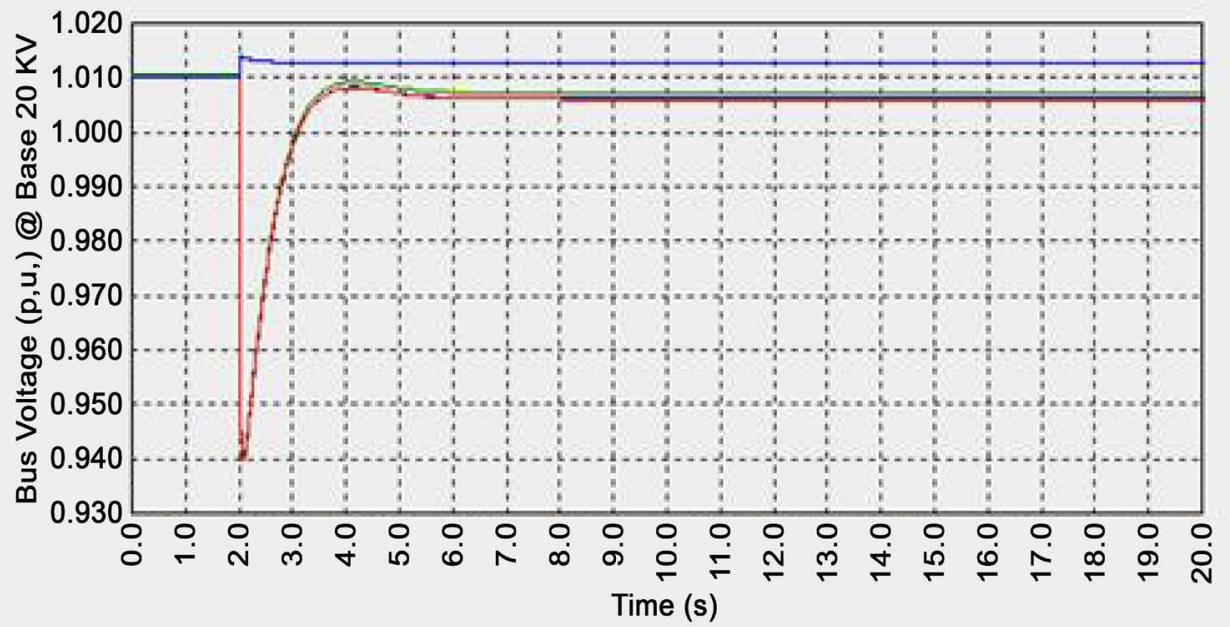

Master-Slave: N2-4-VT Master-Slave: N2-9-VT_— Master-Slave: N2-11-VT— Master-Slave: N2-7-VT — Master-Slave: BUS_2-VT

Figure 9. Simulation results for planned islanding of two diesel and two wind units (case D1). 


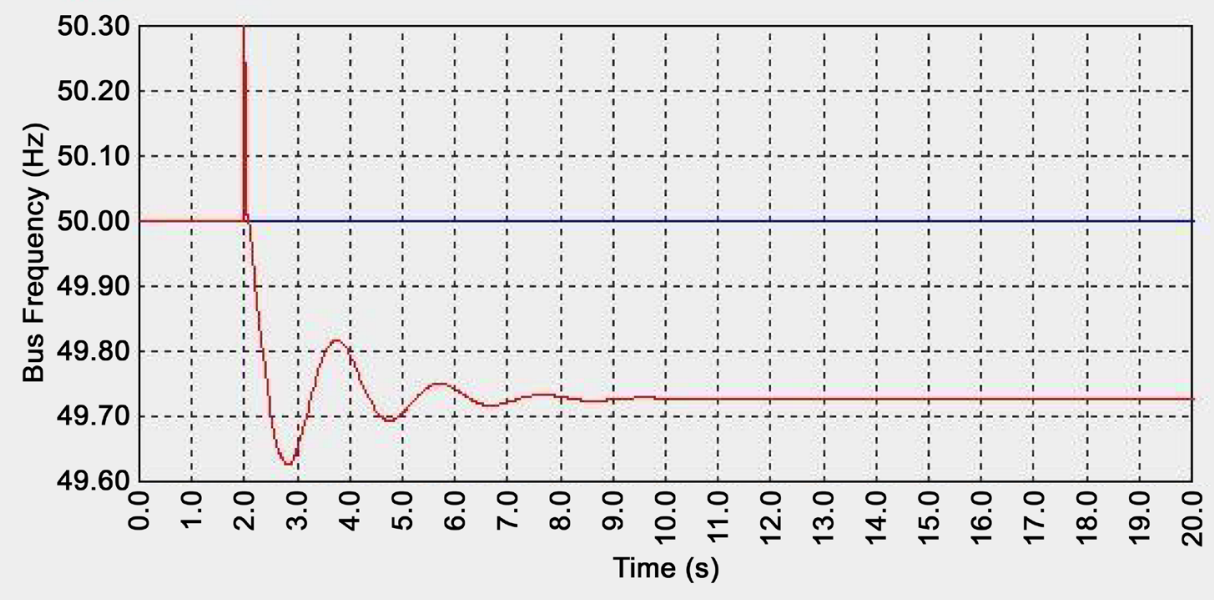

Master-Slave: N2-9-WBL Master-Slave: N2-4-WEI——Master-Slave: N2-9-WEI— Master-Slave: N2-7-WBI——Master-Slave: N2-11-WE

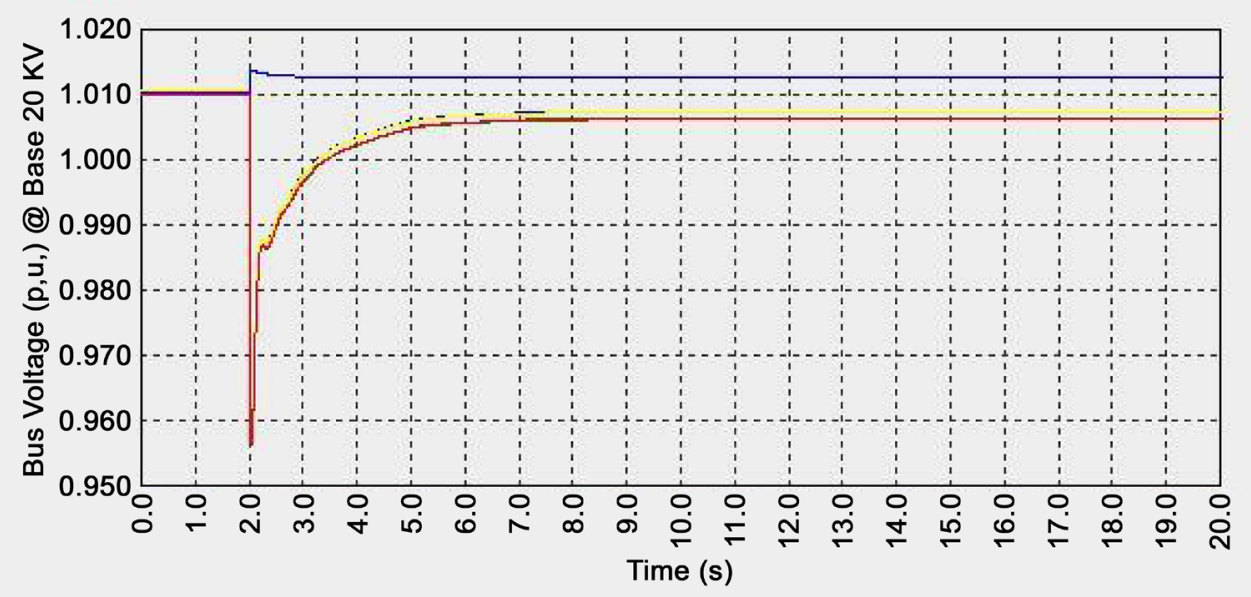

Master-Slave: N2-9-VT Master-Slave: N2-11-VT_ Master-Slave: N2-7-VT — Master-Slave: N2-4-VT — Master-Slave: BUS_2-VT

Figure 10. Simulation results for planned islanding of two gas and two wind units (case D2).

\section{Results}

Table 8 summarizes the main outcomes obtained from this study; hence it gives a brief picture of the problem and the key index to understand it. The table contains also comments about the reasons that the islanding attempt has failed. The planned islanding proved to be feasible option for most of the cases investigated, however some cases' islanding feasibility needed certain agreements between utility and DG units' operators. Besides the unstable behavior of the system following unplanned islanding for all cases tested, it could also lead to DG units' rotor damage, due to the power variations recorded from the individual unplanned sub-case studies.

There is indeed a pivotal role for the anti-islanding protection schemes embedded within distribution networks, since the unintentional islanding effect brings severe outcomes on end users' loads, DG units, and utility assets. This was clear from all of the examined unplanned islanding sub-cases, where DG units were given the permission to 
operate freely without interruption. That was only to demonstrate the size of negative impact it could leave on real distribution systems with DG units, whenever unintentional islanding occurs without having the proper anti-islanding detection and protection schemes.

Frequency variations were related directly to the existing active power mismatch prior to islanding, the type of DG technology, and the governor system associated with them. While voltage variations were function of the existing reactive power mismatch prior to islanding and the type DG unit technology; however only one excitation system was used therefore it was not enough to determine the effect of different excitation systems on voltage behavior.

Operating DG units at close to unity PF will yield better impact on DG units and utility grid during grid-connected mode; however it will cause voltage dips following islanding. A major increase was noticed on all master units loading for all of the cases studied, while PF was reduced simultaneously.

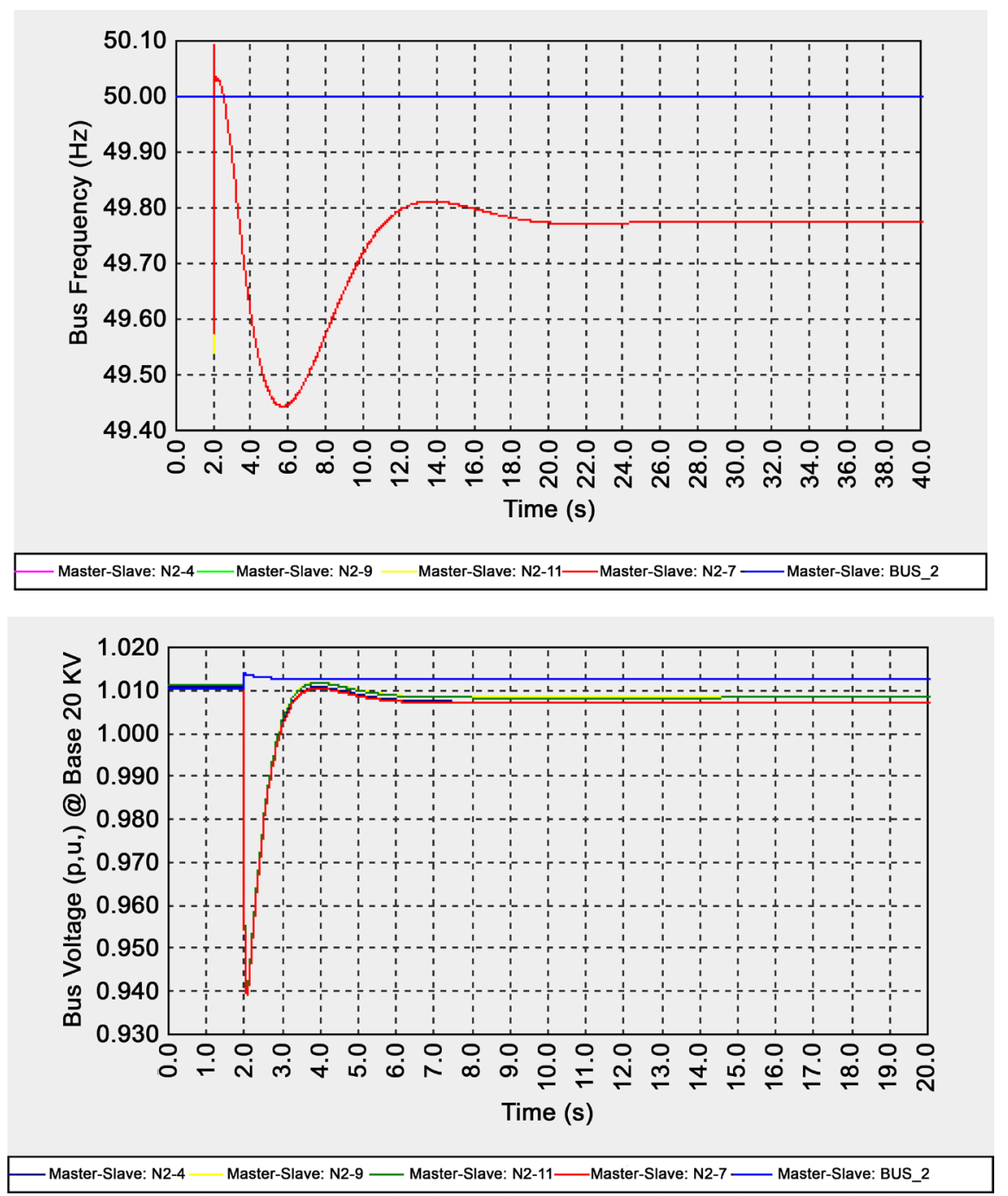

Figure 11. Simulation results for planned islanding of two diesel two wind units (case D3). 
Table 8. Results summary.

\begin{tabular}{cccccc}
\hline DG Technology & Sub-case Number & Results Figure & $\begin{array}{c}\text { Islanding } \\
\text { Scenario }\end{array}$ & $\begin{array}{c}\text { Islanding } \\
\text { Attempt }\end{array}$ & Comment \\
\hline Diesel & A1 & Figure 2 & Planned & Succeeded & Voltage and frequency limit violation \\
& A2 & Figure 3 & Unplanned & Failed & Frequency limit adjusted to t $>5.2$ sec \\
Gas & B1 & Figure 4 & Planned & Conditional Success & Foltage and frequency limit violation \\
Bydro & B2 & Figure 5 & Unplanned & Failed & Frequency limit adjusted to $t>9.6$ sec \\
Wind \& Diesel & C2 & Figure 6 & Planned & Conditional Success & Voltage and frequency limit violation \\
Wind \& Gas & D1 & Figure 9 & Planned & Conditional Success & Islanding is not recommended for prolonged \\
periods to avoid DG rotor over-heating
\end{tabular}

Only one out of the nine master-slave sub-cases returned reliable response (from the diesel subcase A1 study), while three master-slave sub-cases required some certain agreement concerning frequency and voltage settings (B1, C1 and D1 subcases). Finally, five master-slave sub-cases failed to preserve the safe islanding conditions (A2, B2, C2, D2 and D3 subcases).

\section{Conclusions}

The dynamic behavior of a realistic MV network with existing distributed generation following a planned and unplanned islanding has been investigated. The dynamic simulation results were obtained according to different types of DG technologies (wind, hydro, diesel and gas).

The need for dynamic simulation in systems with distributed generation is a necessity for proper islanding planning and abnormal operation prediction. However, certain standards regarding voltage and frequency limits needed to be relaxed in order to make this islanding study possible.

Operating DG units at close to unity PF yields better impact on DG units and utility grid during grid-connected mode; however, it causes voltage dips following islanding. A major increase was noticed on all master units loading for all of the cases studied, while PF was reduced simultaneously.

Finally, with more improved governor and excitation systems, the dynamic behavior of the network during planned islanding could improve. While higher DG units' capacities (or more units injected through network) as well as with higher units' inertia more reliable and stable response will be achieved; hence intentional islanding will be more reasonable in avoiding future unnecessary supply outages.

\section{References}

[1] Conti, S., Nicolosi, R., Rizzo, S.A. and Zeineldin, H.H. (2012) Optimal Dispatching of Dis- 
tributed Generators and Storage Systems for MV Islanded Microgrids. IEEE Transactions on Power Delivery, 27, 1243-1251. http://dx.doi.org/10.1109/TPWRD.2012.2194514

[2] Vita, V., Alimardan, T. and Ekonomou, L. (2015) The Impact of Distributed Generation in the Distribution Networks' Voltage Profile and Energy Losses. Proceedings of the 9 th IEEE European Modelling Symposium on Mathematical Modelling and Computer Simulation, Madrid, 6-8 October 2015, 260-265.

[3] Karimi, M., Mokhlis, H., Naidu, K., Uddin, S. and Bakar, A.H.A. (2016) Photovoltaic Penetration Issues and Impacts in Distribution Network-A Review. Renewable and Sustainable Energy Reviews, 53, 594-605. http://dx.doi.org/10.1016/j.rser.2015.08.042

[4] Franz, P., Talavera, I., Hanson, J. and Sgoff, I. (2015) Optimized Regulation of Dispersed Generation Units for Minimization of Reactive Power Consumption. Proceedings of the IEEE Innovative Smart Grid Technologies Conference (ISGT), Washington DC, 18-20 February 2015, 1-5. http://dx.doi.org/10.1109/isgt.2015.7131798

[5] Vita, V., Ekonomou, L. and Christodoulou, C.A. (2016) The Impact of Distributed Generation to the Lightning Protection of Modern Distribution Lines. Energy Systems, 7, 357-364. http://dx.doi.org/10.1007/s12667-015-0175-3

[6] Prakash, P. and Khatod, D.K. (2016) Optimal Sizing and Siting Techniques for Distributed Generation in Distribution Systems: A Review. Renewable and Sustainable Energy Reviews, 57, 111-130. http://dx.doi.org/10.1016/j.rser.2015.12.099

[7] Karatepe, E., Ugranl, F. and Hiyama, T. (2015) Comparison of Single-and Multiple-Distributed Generation Concepts in Terms of Power Loss, Voltage Profile, and Line Flows under Uncertain Scenarios. Renewable and Sustainable Energy Reviews, 48, 317-327. http://dx.doi.org/10.1016/j.rser.2015.04.027

[8] Chowdhury, S.P., Chowdhury, S., Ten, C.F. and Crossley, P.A. (2009) Operation and Control of DG Based Power Island in Smart Grid Environment. Proceedings of the 20 th International Conference and Exhibition on Electricity Distribution, Part 1, Prague, 8-11 June 2009, 8-11.

[9] National Grid (2010) Working Group Report: Small Embedded Generation Issue 1.0.

[10] Massucco, S., Pitto, A. and Silvestro, F.A. (2011) Gas Turbine Model for Studies on Distributed Generation Penetration into Distribution Networks. IEEE Transactions on Power Systems, 26, 992-999. http://dx.doi.org/10.1109/TPWRS.2010.2091290

[11] Balaguer, I., Lei, Q., Yang, S., Supatti, U. and Peng, F.Z. (2011) Control for Grid-Connected and Intentional Islanding Operations of Distributed Power Generation. IEEE Transactions on Industrial Electronics, 58, 147-157. http://dx.doi.org/10.1109/TIE.2010.2049709

[12] Chen, Y., Xu, Z. and Ostergaard, J. (2008) Frequency Analysis for Planned Islanding Operation in the Danish Distribution System. Proceedings of 43 rd International Universities Power Engineering Conference, Bornholm, 1-4 September 2008, 1-5.

[13] Shahabi, M., Haghifam, M.-R., Mohamadian, M. and Nabavi-Niaki, S. (2009) Dynamic Behavior Improvement in a Microgrid with Multiple DG Units Using a Power Sharing Approach. Proceedings of the IEEE PowerTech, Bucharest, 28 June-2 July 2009, 1-8.

[14] Mulhausen, J., Schaefer, J., Mynam, M., Guzman, A. and Donolo M. (2010) Anti-Islanding Today, Successful Islanding in the Future. Proceedings of the $63 \mathrm{rd}$ Annual Conference for Protective Relay Engineers, College Station, 29 March-1 April 2010, 1-8. http://dx.doi.org/10.1109/cpre.2010.5469490

[15] Mohamad, H., Mokhlis, H., Bakar, A.H.A. and Ping, H.W. (2011) A Review on Islanding Operation and Control for Distribution Network Connected with Small Hydro Power Plant. Renewable and Sustainable Energy Reviews, 15, 3952-3962. 
http://dx.doi.org/10.1016/j.rser.2011.06.010

[16] Trujillo, C., Velasco, D., Figueres, E. and Garcera, G. (2010) Local and Remote Techniques for Islanding Detection in Distributed Generators. InTech Publication.

http://dx.doi.org/10.5772/8883

[17] Mahat, P., Chen, Z. and Bak-Jensen, B. (2008) Review of Islanding Detection Methods for Distributed Generation. Proceedings of the 3rd International Conference on Electric Utility Deregulation and Restructuring and Power Technologies, Nanjing, 6-9 April 2008, 27432748. http://dx.doi.org/10.1109/drpt.2008.4523877

[18] Maki, K., Kulmala, A., Repo, S. and Jarventausta, P. (2007) Problems Related to Islanding Protection of Distributed Generation in Distribution Network. Proceedings of the IEEE PowerTech, Lausanne, 1-5 July 2007, 467-472. http://dx.doi.org/10.1109/pct.2007.4538362

[19] Velasco, D., Trujillo, C., Garcerá, G. and Figueres, E. (2010) Review of Anti-Islanding Techniques in Distributed Generators. Renewable and Sustainable Energy Reviews, 14, 1608-1614. http://dx.doi.org/10.1016/j.rser.2010.02.011

[20] Katiraei, F., Abbey, C., Tang, S. and Gauthier, M. (2008) Planned Islanding on Rural Feeders-Utility Perspective. Proceedings of the IEEE Power and Energy Society General Meeting, Pittsburgh, 20-24 July 2008, 1-6. http://dx.doi.org/10.1109/PES.2008.4596774

[21] Bründlinger, R. and Bletterie, B. (2005) Unintentional Islanding in Distribution Grids with a High Penetration of Inverter-Based DG: Probability for Islanding and Protection Methods. Proceedings of the IEEE PowerTech, St Petersburg, 27-30 June, 2005, 1-7. http://dx.doi.org/10.1109/ptc.2005.4524519

[22] IEEE Application Guide for IEEE Std 1547 (TM) (2009) IEEE Standard for Interconnecting Distributed Resources with Electric Power Systems. 1547. 2-2008.

[23] Basso, T.S. and DeBlasio, R. (2004) IEEE 1547 Series of Standards: Interconnection Issues. IEEE Transactions on Power Electronics, 19, 1159-1162. http://dx.doi.org/10.1109/TPEL.2004.834000

[24] Ozeer, B.A., Hernandez-Gonzalez, G. and El-Fouly, T.H. (2012) Investigation of Planned Islanding Performance of Rotating Machine-Based DG Technologies. 2nd Edition, Natural Resources Canada.

[25] Vijayan, R., Subrahmanyam, C. and Ranjit, R. (2012) Dynamic Modeling of Microgrid for Grid Connected and Intentional Islanding Operation. Proceedings of the International Conference on Advances in Power Conversion and Energy Technologies (APCET), Mylavaram, 2-4 August, 2012, 1-6. http://dx.doi.org/10.1109/APCET.2012.6302055

[26] Pei, Y., Jiang, G., Yang, X. and Wang, Z. (2004) Auto-Master-Slave Control Technique of Parallel Inverters in Distributed AC Power Systems and UPS. Proceedings of the 35 th IEEE Annual Power Electronics Specialists Conference, 20-25 June 2004, 2050-2053.

[27] Conti, S., Greco, A., Messina, N. and Vagliasindi, U. (2008) Intentional Islanding of MV Microgrids: Discussion of a Case Study and Analysis of Simulation Results. Proceedings of the International Symposium on Power Electronics, Electrical Drives, Automation and Motion, Catania, 11-13 June 2008, 422-427. http://dx.doi.org/10.1109/speedham.2008.4581285

[28] Navarro, I.R. (2002) Dynamic Load Models for Power Systems-Estimation of Time-Varying Parameters during Normal Operation. PhD Thesis, Lund University, Lund.

[29] Stojanović, D.P., Korunović, L.M. and Milanović, J. (2008) Dynamic Load Modelling Based on Measurements in Medium Voltage Distribution Network. Electric Power Systems Research, 78, 228-238. http://dx.doi.org/10.1016/j.epsr.2007.02.003

[30] Li, Y., Chiang, H.D., Choi, B.K., Chen, Y.T., Huang, D.H. and Lauby, M.G. (2008) Load Models for Modeling Dynamic Behaviors of Reactive Loads: Evaluation and Comparison. 
International Journal of Electrical Power \& Energy Systems, 30, 497-503.

http://dx.doi.org/10.1016/j.ijepes.2008.04.007

[31] Achilles, S. and Poller, M. (2003) Direct Drive Synchronous Machine Models for Stability Assessment of Wind Farms. Proceeding of the 4th International Workshop on Large Scale Integration of Wind Power and Transmission Networks for Offshore Wind Farms, Billund, 20-21 October 2003, 1-9.

[32] Karimi, H., Davison, E. and Iravani, R. (2010) Multivariable Servomechanism Controller for Autonomous Operation of a Distributed Generation Unit: Design and Performance Evaluation. IEEE Transactions on Power Systems, 25, 853-865.

http://dx.doi.org/10.1109/TPWRS.2009.2031441

[33] Bahrani, B., Karimi, H. and Iravani, R. (2010) Stability Analysis and Experimental Validation of a Control Strategy for Autonomous Operation of Distributed Generation Units. Proceeding of the International Power Electronics Conference (IPEC), Sapporo, 21-24 June 2010, 464-471.

Submit or recommend next manuscript to SCIRP and we will provide best service for you:

Accepting pre-submission inquiries through Email, Facebook, LinkedIn, Twitter, etc.

A wide selection of journals (inclusive of 9 subjects, more than 200 journals)

Providing 24-hour high-quality service

User-friendly online submission system

Fair and swift peer-review system

Efficient typesetting and proofreading procedure

Display of the result of downloads and visits, as well as the number of cited articles

Maximum dissemination of your research work

Submit your manuscript at: http://papersubmission.scirp.org/

Or contact jpee@scirp.org 